\title{
BMJ
}

\section{Psychosis alters association between IQ and future risk of attempted suicide: cohort study of 1109475 Swedish men}

\author{
G David Batty, Wellcome Trust fellow, ${ }^{1,2,3}$ Elise Whitley, medical statistician, ${ }^{1}$ Ian I Deary, professor of \\ differential psychology, ${ }^{2}$ Catharine R Gale, reader in epidemiology, ${ }^{4}$ Per Tynelius, statistician, ${ }^{5}$ \\ Finn Rasmussen, professor $^{5}$
}

${ }^{1}$ Medical Research Council Social and Public Health Sciences Unit, University of Glasgow, Glasgow

${ }^{2}$ Centre for Cognitive Ageing and Cognitive Epidemiology, Department of Psychology, University of Edinburgh, Edinburgh

${ }^{3}$ The George Institute for International Health, University of Sydney, Sydney, Australia

${ }^{4}$ Medical Research Council Epidemiology Resource Centre, University of Southampton, Southampton

${ }^{5}$ Child and Adolescent Public Health Epidemiology Group, Department of Public Health Sciences, Karolinska Institute, SE17176 Stockholm, Sweden

Correspondence to: F Rasmussen finn.rasmussen@ki.se

Cite this as: BMJ 2010;340:c2506 doi:10.1136/bmj.c2506

\section{ABSTRACT}

Objectives To explore associations between IQ measured in early adulthood and subsequent hospital admissions for attempted suicide and to explore the role of psychosis and examine associations of IQ with specific methods of attempted suicide.

Design Cohort study.

Setting Sweden.

Participants 1109475 Swedish men with IQ measured in early adulthood followed up for an average 24 years.

Main outcome measures Hospital admission for attempted suicide.

Results 17736 (1.6\%) men had at least one hospital admission for attempted suicide by any means during follow-up. After adjustment for age and socioeconomic status, lower IQ scores were associated with an elevated risk of attempted suicide by any means (hazard ratio per standard deviation decrease in $\mathrm{IQ}=1.57,95 \%$ confidence interval 1.54 to 1.60 ), with stepwise increases in risk across the full IQ range ( $P$ for trend 0.001 ). Similar associations were observed for all specific methods of attempted suicide. Separate analyses indicated that associations between IQ and attempted suicide were restricted to participants without psychosis and that IQ had no marked impact on risk of attempted suicide in those with psychosis.

Conclusions Low IQ scores in early adulthood were associated with a subsequently increased risk of attempted suicide in men free from psychosis. A greater understanding of the mechanisms underlying these associations may provide opportunities and strategies for prevention.

\section{INTRODUCTION}

Attempted (non-fatal) suicide is a frequent cause of emergency admission to hospital in Europe and the United States, ${ }^{12}$ and repeated episodes are common. ${ }^{13}$ Unsurprisingly, attempted suicide is the strongest predictor of completed (fatal) suicide; estimates in the United Kingdom suggest that up to two thirds of suicides are preceded by a non-fatal attempt in the previous year. ${ }^{3}$ Growing evidence suggests that intelligence (cognitive function) may have a role in the aetiology of attempted suicide, but the nature of this relation is uncertain. Evidence from ecological studies suggests that countries with higher average scores on intelligence tests generally have higher suicide rates, although these findings may well be subject to the ecological fallacy. ${ }^{45}$ Conversely, observations in nonclinical samples indicate that people with lower intelligence are more likely to attempt suicide, ${ }^{6-8}$ and to succeed in killing themselves, ${ }^{9-12}$ consistent with evidence that psychiatric illness is more common in people with lower IQ scores. ${ }^{13}$ However, the presence of psychiatric illness, specifically schizophrenia or psychosis, has been hypothesised to modify associations between IQ and death from suicide; in people with psychosis, those with higher IQ or better school performance had the greatest risk of completed suicide. $^{121415}$

Previous studies examining intelligence and attempted suicide have not directly considered the role of psychosis. Furthermore, they were based on relatively small numbers of participants or events, ${ }^{6-8}$ leading to limited statistical power and prohibiting exploration of associations of IQ with attempted suicide by specific means. The analysis presented here explores associations between IQ measured in early adulthood and subsequent hospital admissions for attempted suicide in a cohort of more than a million Swedish men, of whom more than 15000 attempted suicide during two decades of follow-up. This cohort is more than seven times larger than the previous largest study. ${ }^{6}$ In addition to offering greater statistical power, this has allowed exploration of the role of psychosis and examination of associations of IQ with specific methods of attempted suicide.

\section{METHODS}

Study participants and record linkage

The record linkage used to generate this cohort has been reported previously. ${ }^{10} 16$ The cohort comprised all non-adopted men born in Sweden from 1950 to 1976 with both biological parents identified in the multi-generation register. We used unique personal identification numbers to link this register with the population and housing censuses records (1960 and 1970), and military service conscription, cause of 
death, and national hospital discharge registers, resulting in 1379531 successful matches.

\section{Conscription examination}

The military service conscription examination involves a structured, standard medical assessment of physical and mental health and cognitive function. During the years covered by this study, the law required this examination; only men of foreign citizenship or with severe disability were excused. This dataset covers examinations from 15 September 1969 to 31 December 1994, after which the method for measuring IQ changed. Average age at examination was 18.3 (range 16-25) years.

IQ was measured by four written subtests representing verbal, logical, spatial, and technical abilities. ${ }^{17}$ The verbal test measured knowledge of synonyms. The logical test measured capacity to understand written instructions and apply them to problem solving. The spatial test depicted a plan drawing of an object in its pre-assembled, two dimensional state and required respondents to identify, from a series of drawings of fully assembled, three dimensional objects, which it represented. The technical test measured knowledge of chemistry and physics and implies a general knowledge component. All test scores, including a total IQ score derived from summing the results of the subtests, were standardised year on year to give a Gaussian distributed integer score between 1 and 9, with higher values indicating greater intellectual capacity.

Psychosis at conscription was identified during a short interview by a physician (ICD-8/9 (international classification of diseases, 8 th/9th revision) codes 295.0299.9). Medical personnel used standard protocols to measure blood pressure, height, and weight. Body mass index was derived in the usual way (weight $(\mathrm{kg})$ / height $\left.(\mathrm{m})^{2}\right)$. Childhood socioeconomic status was based on the highest occupation of either parent (from 1960/1970 population and housing censuses), using seven categories: non-manual (high), non-manual (intermediate), non-manual (low), farmers, skilled, unskilled, and other. Highest educational achievement

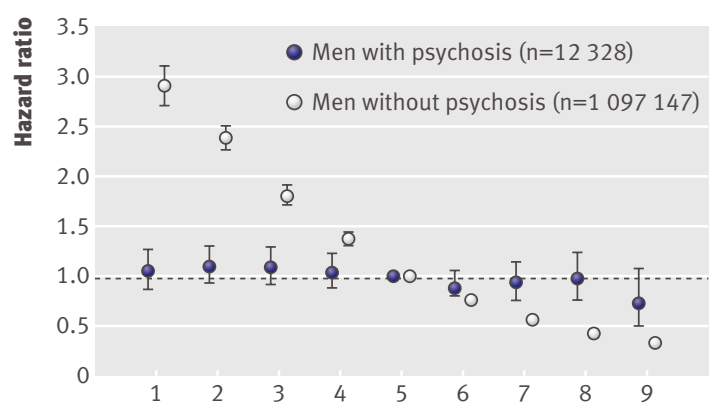

IQ score

Age adjusted hazard ratio (95\% confidence interval) for attempted suicide (intentional and undetermined causes combined) by any means according to IQ score in men with and without psychosis (on basis of conscription examination or hospital admissions pre-dating any admissions for attempted suicide)
(1990-2004) was also based on seven categories: primary school ( $<9$ years), primary school (9-10 years), secondary school ( $\leq 12$ years), full secondary education, university ( $<3$ years), university ( $\geq 3$ years), and $\mathrm{PhD}$ studies. We used population and housing censuses records (1990) to ascertain adult socioeconomic status coded as for childhood status. Adult socioeconomic status was based on men's own occupation for those who had an occupational code and otherwise on household socioeconomic status. Questionnaire data on smoking and alcohol consumption were collected at conscription in 1969-70 for a subgroup (3\%) of men. "Risky" use of alcohol was identified from at least one of consumption of $\geq 250 \mathrm{~g} 100 \%$ alcohol per week, ever consumed alcohol during a hangover, ever been apprehended for drunkenness, and often been drunk. ${ }^{18}$

\section{Hospital admissions data}

Hospital admissions data from 1969-2006 were based on the Swedish hospital discharge register, which covered around a third of the Swedish population in 1970, rising to $71 \%$ in 1977 and $100 \%$ from 1987 . The shortfall in the 1970s and 1980s occurred in counties of varying population density and socioeconomic composition, and we have no reason to suppose that any systematic difference existed in associations of IQ with attempted suicide between counties included and not included in the register during these early years. Admissions were coded according to ICD versions 8,9 , and 10. We identified attempted (non-fatal) suicides from injuries coded as intentional or undetermined. Although likely to vary from hospital to hospital, "undetermined" codes generally describe injuries for which level of intent is difficult to establish. However, in adults, most undetermined injuries are likely to have been intentional, ${ }^{19}$ and the two codes are usually combined in epidemiological studies. Our follow-up period covered three ICD revisions, and, although these revisions do not seem to have affected the total number of suicides, differences exist in the classifications of specific suicide methods. ${ }^{20}$ We therefore identified seven methods that were coded consistently between revisions ${ }^{2021}$ : poisoning by solid or liquid (including drugs); other poisoning (including domestic gas and vehicle exhaust); hanging, strangulation, and suffocation; drowning; firearms and explosives; jumping or falling from a high place; and sharp objects. Table 1 shows the ICD codes used to identify hospital admissions for attempted suicide. We restricted all analyses to admissions for attempted suicide that occurred after conscription. We also identified hospital admis sions for psychosis occurring before any suicide attempts (ICD 8/9: 295.0-299.9; ICD10: F20.0F29.9). Analyses based on specific psychotic conditions were very similar to those based on general psychosis; we therefore present results for general psychosis for simplicity and consistency with previous studies. 
Table 1|Number of men with one or more hospital admission for attempted suicide* during follow-up ( $\mathrm{n}=1$ 109 475)

\begin{tabular}{|c|c|c|c|}
\hline Attempted suicides & ICD $8 / 9$ codes & ICD 10 codes & No† \\
\hline All & E950-E959, E980-E989 & $X 60-X 84, Y 10-Y 34$ & 17736 \\
\hline Poisoning by solid or liquid substances & E950, E980 & X60-X65, X68-X69, Y10-Y15, Y18-Y19 & 14058 \\
\hline Sharp object & E956, E986 & $\mathrm{X} 78, \mathrm{Y} 28$ & 1646 \\
\hline Other poisoning & E951-E952, E981-E982 & $\mathrm{X} 66-\mathrm{X} 67, \mathrm{Y} 16-\mathrm{Y} 17$ & 455 \\
\hline Hanging, strangulation, and suffocation & E953, E983 & $\mathrm{X} 70, \mathrm{Y} 20$ & 425 \\
\hline Jumping from high place & E957, E987 & $\mathrm{X} 80, \mathrm{Y} 30$ & 373 \\
\hline Firearms and explosives & E955, E985 & $X 72-X 75, Y 22-Y 25$ & 218 \\
\hline Drowning and submersion & E954, E984 & $\mathrm{X} 71, \mathrm{Y} 21$ & 105 \\
\hline
\end{tabular}

*Includes undetermined injuries.

†Men could have more than one type of suicide attempt.

\section{Statistical methods}

We used Cox proportional hazards regression to explore associations between IQ and attempted suicide after checking that proportional hazards assumptions were not violated. As we included all hospital admissions, men could have more than one suicide attempt recorded. We based the main analyses on the first attempt by any means or by one of our seven specific methods. A man with two admissions for intentional jumping and one for intentional hanging would thus be treated as an attempted suicide event in analyses of all attempted suicides (first event), intentional jumping (first intentional jump), and intentional hanging (only hanging). Follow-up began on the date of conscription and ended on the earliest of date of first attempted suicide (by any means or by specific method as appropriate), death, emigration, or 31 December 2006. The main analyses were based on the total IQ score. We calculated hazard ratios and 95\% confidence intervals for all attempted suicides combined according to IQ in nine categories relative to the median $(\mathrm{IQ}=5)$ and a standard deviation decrease in IQ. Analyses of method specific attempted suicides were based on fewer events, and we calculated hazard ratios $(95 \%$ confidence intervals) for IQ in four groups (7-9, 5-6, 3$4,1-2)$ to preserve statistical power and for ease of presentation across all methods.

We adjusted all analyses for age at conscription. Separate models adjusted for childhood circumstances, based on childhood socioeconomic status and adult height (although largely under genetic control, adult stature is a widely used indicator of preadult suboptimal nutrition and socioeconomic adversity $^{22}$, and adult socioeconomic status. Blood pressure and body mass index have been associated with both IQ and suicide, ${ }^{23-26}$ and we also included these as potential confounding factors. Multiply adjusted models also included conscription centre and year of birth. We examined adjustments for educational achievement separately because of its strong correlation with IQ. Analyses were based on men with complete data for all variables.

Heavy drinking and binge drinking have been previously linked with lower IQ and increased suicide risk. ${ }^{27-29}$ In addition, smoking may be a proxy measure for risk taking or poor health behaviours. In the subgroup of men with complete data, we assessed the impact of adjusting associations between IQ and attempted suicide for smoking (smoker $v$ non-smoker) and alcohol (risky alcohol use $v$ not).

We identified men with psychosis from diagnoses of psychosis at the conscription examination and from hospital admissions for psychosis pre-dating any attempted suicide admissions. We calculated associations between IQ and attempted suicide separately for men with and without psychosis and did corresponding tests of statistical interaction/effect modification. Finally, we repeated the main analyses excluding the

Table 2 |Characteristics of 1109475 men included in analyses. Values are numbers (percentages) unless stated otherwise

\begin{tabular}{|c|c|c|c|c|}
\hline Characteristics & \multicolumn{4}{|c|}{ IQ score } \\
\hline Mean (SD) age (years) & $18.3(0.6)$ & $18.2(0.6)$ & $18.3(0.6)$ & $18.4(0.6)$ \\
\hline Mean (SD) body mass index $\left(\mathrm{kg} / \mathrm{m}^{2}\right)$ & $21.9(3.4)$ & $21.8(3.0)$ & $21.6(2.7)$ & $21.4(2.5)$ \\
\hline Mean (SD) systolic blood pressure $(\mathrm{mm} \mathrm{Hg})$ & $128.5(11.0)$ & $128.4(10.8)$ & $128.5(10.8)$ & $128.6(10.9)$ \\
\hline Participant in non-manual occupation & $7814(7.5)$ & $42403(15.4)$ & $116188(26.2)$ & $118296(41.3)$ \\
\hline University educated & $3561(3.4)$ & $31603(11.5)$ & $145599(32.8)$ & $192593(67.2)$ \\
\hline Any psychosis* & $2728(2.6)$ & $3665(1.3)$ & $3947(0.9)$ & $1988(0.7)$ \\
\hline Any hospital admission for attempted suicide $†$ & $3851(3.7)$ & $6182(2.2)$ & $5631(1.3)$ & $2072(0.7)$ \\
\hline
\end{tabular}

*Based on conscription examination or hospital admissions pre-dating any admissions for attempted suicide.

†Includes undetermined injuries. 
quarter of admissions for attempted suicide due to undetermined injuries, separately for the four IQ subscales, and using Poisson regression for attempted suicide rates based on the total number of admissions.

\section{RESULTS}

Of 1379531 men in the original cohort, 1109475 $(80.4 \%)$ had complete data on IQ and confounding variables and were included in the analyses. The most common reason for exclusion was missing IQ $(n=$ 213861 ). Men with missing data had lower socioeconomic status and educational attainments. Men were followed up for an average 24.2 years. Altogether $17736(1.6 \%)$ men included in the analyses had at least one admission for attempted suicide during follow-up compared with 2561 (1.0\%) men with missing data. The most common method of attempted suicide was poisoning by solid or liquid (1.3\% of men), followed by injury with a sharp object $(0.1 \%)$, other poisoning $(0.04 \%)$, hanging, strangulation, or suffocation $(0.04 \%)$, jumping or falling from a high place $(0.03 \%)$, injury from firearms or explosives $(0.02 \%)$, and drowning or submersion $(0.01 \%)$ (table 1$)$.

Table 2 shows the characteristics of men included in the analyses. Men with lower IQ scores were somewhat shorter and had slightly higher body mass index. Differences in socioeconomic status and education were stepwise: men with lower IQ scores were increasingly less likely to have parents from a nonmanual socioeconomic status, to have a non-manual socioeconomic status, or to be university educated. A total of $12328(1.1 \%)$ men included in the analyses were identified as psychotic; $280(2.3 \%)$ were identified at conscription and the remainder had a subsequent hospital admission for psychosis pre-dating any admissions for attempted suicide. Psychosis and attempted suicide were both more common in men with lower IQ scores.
Table 3 shows hazard ratios for attempted suicide by any means according to IQ score relative to the median $(\mathrm{IQ}=5)$. We found consistent stepwise increases in hazard across all nine IQ groups ( $\mathrm{P}$ for trend $<0.001)$. In age adjusted analyses, men in the lowest IQ group were almost nine times as likely to have an admission for attempted suicide as were those in the highest group, and an SD (1.9 point) decrease in IQ score was associated with a $71 \%$ (95\% confidence interval $68 \%$ to $74 \%$ ) increase in hazard. Adjustment for body mass index and blood pressure had no effect on these associations (results available on request). Associations were somewhat weakened by adjustments for childhood and adult socioeconomic status and, most notably, education. However, striking gradients of increasing attempted suicide with decreasing IQ score remained in multiply adjusted models.

Table 4 shows similar results for attempted suicides by specific methods. Hazard ratios are shown for four categories of IQ score relative to the median (IQ score $=5$ or 6 ). Again, we found stepwise increases in age adjusted hazard with decreasing IQ for all types of attempted suicide, most markedly for the two most common methods: poisoning by solid or liquid (age adjusted hazard ratio for an SD decrease in $\mathrm{IQ}=1.76$, $95 \%$ confidence interval 1.73 to 1.79 ) and injuries from sharp objects $(1.73,1.65$ to 1.82$)$. Adjustments for socioeconomic status and, particularly, education led to attenuation of associations between IQ and attempted suicide by all methods other than drowning, for which adjustment had no marked impact.

Smoking and alcohol data were available for a subgroup of 34034 men $(3.1 \%$ of those included in the main analyses), of whom $783(2.3 \%)$ had at least one hospital admission for attempted suicide. Adjustment for smoking and risky alcohol use both to led attenuation of associations of IQ with attempted suicide by any means (hazard ratio for an SD decrease in IQ adjusted

\begin{tabular}{|c|c|c|c|c|c|c|}
\hline & $\begin{array}{l}\text { No (attempted suicide/ } \\
\text { no attempted suicide) }\end{array}$ & Adjusted for age & $\begin{array}{l}\text { Adjusted for age and } \\
\text { childhood SES } †\end{array}$ & $\begin{array}{l}\text { Adjusted for age and } \\
\text { adult SES }\end{array}$ & $\begin{array}{l}\text { Multiple adjustment } \\
\text { (excluding education) }\end{array}$ & $\begin{array}{l}\text { Multiple adjustment§} \\
\text { (including education) }\end{array}$ \\
\hline \multicolumn{7}{|l|}{ IQ score: } \\
\hline 9 & $238 / 49237$ & $0.33(0.29$ to 0.37$)$ & 0.35 (0.31 to 0.40$)$ & 0.34 (0.29 to 0.38$)$ & 0.37 (0.32 to 0.42$)$ & 0.57 (0.50 to 0.65$)$ \\
\hline 8 & $602 / 89907$ & 0.45 (0.41 to 0.49$)$ & $0.48(0.44$ to 0.52$)$ & $0.47(0.43$ to 0.51$)$ & $0.50(0.46$ to 0.54$)$ & $0.69(0.63$ to 0.75$)$ \\
\hline 7 & $1232 / 145293$ & $0.57(0.53$ to 0.61$)$ & $0.59(0.56$ to 0.63$)$ & $0.59(0.56$ to 0.63$)$ & $0.62(0.58$ to 0.66$)$ & $0.76(0.71$ to 0.81$)$ \\
\hline 6 & 2 169/192187 & $0.76(0.72$ to 0.80$)$ & 0.78 (0.74 to 0.82$)$ & $0.79(0.75$ to 0.83$)$ & 0.80 (0.76 to 0.84$)$ & 0.88 (0.83 to 0.93$)$ \\
\hline 5 & $3462 / 245694$ & 1.00 (reference) & 1.00 (reference) & 1.00 (reference) & 1.00 (reference) & 1.00 (reference) \\
\hline 4 & $3266 / 159540$ & $1.36(1.30$ to 1.43$)$ & $1.34(1.28$ to 1.40$)$ & 1.37 (1.31 to 1.44$)$ & $1.32(1.26$ to 1.38$)$ & 1.23 (1.17 to 1.29$)$ \\
\hline 3 & $2916 / 109284$ & 1.79 (1.70 to 1.88$)$ & 1.73 (1.64 to 1.82$)$ & 1.75 (1.66 to 1.83$)$ & 1.65 (1.57 to 1.74$)$ & $1.48(1.41$ to 1.55$)$ \\
\hline 2 & $2478 / 70270$ & $2.36(2.24$ to 2.48$)$ & $2.24(2.13$ to 2.36$)$ & 2.21 (2.10 to 2.33$)$ & 2.07 (1.96 to 2.18$)$ & 1.79 (1.70 to 1.88$)$ \\
\hline 1 & $1373 / 30327$ & $2.92(2.74$ to 3.11$)$ & $2.73(2.57$ to 2.91$)$ & $2.60(2.44$ to 2.77$)$ & $2.36(2.21$ to 2.51$)$ & 1.99 (1.87 to 2.12$)$ \\
\hline P valueף & & $<0.001$ & $<0.001$ & $<0.001$ & $<0.001$ & $<0.001$ \\
\hline SD decrease & $17736 / 1091739$ & 1.71 (1.68 to 1.74$)$ & 1.65 (1.62 to 1.68$)$ & 1.64 (1.62 to 1.67$)$ & 1.57 (1.54 to 1.60$)$ & $1.38(1.36$ to 1.41$)$ \\
\hline Pvalue & & $<0.001$ & $<0.001$ & $<0.001$ & $<0.001$ & $<0.001$ \\
\hline
\end{tabular}

SES=socioeconomic status.

*Intentional and undetermined injuries combined.

†Childhood SES and height.

¥Adjusted for age, conscription centre, year of birth, childhood SES, adult SES, height, body mass index, and systolic blood pressure.

§Adjusted for age, conscription centre, year of birth, childhood SES, adult SES, height, body mass index, systolic blood pressure, and educational attainment.

TP for trend. 
Table 4 | Hazard ratios (95\% confidence intervals) for method specific attempted suicide* according to IQ

\begin{tabular}{|c|c|c|c|c|}
\hline IQ score & $\begin{array}{l}\text { No (attempted suicide/no } \\
\text { attempted suicide) }\end{array}$ & Adjusted for age & $\begin{array}{l}\text { Multiple adjustment } \dagger \\
\text { (excluding education) }\end{array}$ & $\begin{array}{l}\text { Multiple adjustmentł } \\
\text { (including education) }\end{array}$ \\
\hline \multicolumn{5}{|c|}{ Poisoning (solid or liquid) } \\
\hline 7-9 & $1559 / 284950$ & $0.53(0.50$ to 0.56$)$ & $0.58(0.55$ to 0.61$)$ & 0.75 (0.71 to 0.80$)$ \\
\hline $5 / 6$ & $4366 / 439146$ & 1.00 (reference) & 1.00 (reference) & 1.00 (reference) \\
\hline $3 / 4$ & $4988 / 270018$ & $1.79(1.72$ to 1.86$)$ & 1.65 (1.58 to 1.72$)$ & $1.44(1.38$ to 1.50$)$ \\
\hline $1 / 2$ & $3145 / 101303$ & 2.98 (2.85 to 3.12$)$ & 2.45 (2.34 to 2.57 ) & 1.99 (1.90 to 2.09 ) \\
\hline Pvalue§ & & $<0.001$ & $<0.001$ & $<0.001$ \\
\hline SD decrease & $14058 / 1095417$ & $1.76(1.73$ to 1.79$)$ & $1.60(1.58$ to 1.63$)$ & $1.40(1.38$ to 1.43$)$ \\
\hline$P$ value & & $<0.001$ & $<0.001$ & $<0.001$ \\
\hline \multicolumn{5}{|l|}{ Sharp object } \\
\hline $7-9$ & $183 / 286326$ & 0.51 (0.43 to 0.61$)$ & $0.55(0.46$ to 0.65$)$ & $0.70(0.59$ to 0.84$)$ \\
\hline $5 / 6$ & $530 / 442982$ & 1.00 (reference) & 1.00 (reference) & 1.00 (reference) \\
\hline $3 / 4$ & $562 / 274444$ & 1.65 (1.47 to 1.86$)$ & $1.53(1.36$ to 1.73$)$ & 1.35 (1.19 to 1.52$)$ \\
\hline $1 / 2$ & $371 / 104077$ & $2.86(2.50$ to 3.26$)$ & 2.35 (2.05 to 2.70$)$ & 1.96 (1.71 to 2.26$)$ \\
\hline Pvalue§ & & $<0.001$ & $<0.001$ & $<0.001$ \\
\hline SD decrease & $1646 / 1107829$ & 1.73 (1.65 to 1.82$)$ & 1.60 (1.51 to 1.68$)$ & 1.41 (1.33 to 1.49$)$ \\
\hline$P$ value & & $<0.001$ & $<0.001$ & $<0.001$ \\
\hline \multicolumn{5}{|c|}{ Other poisoning } \\
\hline $7-9$ & $56 / 286453$ & $0.56(0.41$ to 0.76$)$ & $0.64(0.47$ to 0.88$)$ & $0.80(0.58$ to 1.10$)$ \\
\hline $5 / 6$ & $153 / 443359$ & 1.00 (reference) & 1.00 (reference) & 1.00 (reference) \\
\hline $3 / 4$ & $170 / 274836$ & 1.75 (1.40 to 2.17$)$ & 1.54 (1.23 to 1.93$)$ & 1.38 (1.10 to 1.72$)$ \\
\hline $1 / 2$ & $76 / 104372$ & 2.06 (1.56 to 2.71$)$ & $1.63(1.23$ to 2.17$)$ & 1.39 (1.04 to 1.86$)$ \\
\hline Pvalue§ & & $<0.001$ & $<0.001$ & 0.002 \\
\hline SD decrease & $455 / 1109020$ & 1.55 (1.41 to 1.70$)$ & 1.38 (1.24 to 1.52$)$ & $1.22(1.10$ to 1.36$)$ \\
\hline$P$ value & & $<0.001$ & $<0.001$ & $<0.001$ \\
\hline \multicolumn{5}{|c|}{ Hanging, strangulation, and suffocation } \\
\hline $7-9$ & $66 / 286443$ & $0.71(0.53$ to 0.96$)$ & $0.77(0.57$ to 1.04$)$ & $0.98(0.72$ to 1.34$)$ \\
\hline $5 / 6$ & $140 / 443372$ & 1.00 (reference) & 1.00 (reference) & 1.00 (reference) \\
\hline $3 / 4$ & $139 / 274867$ & 1.57 (1.24 to 1.99$)$ & $1.47(1.15$ to 1.86$)$ & $1.25(0.99$ to 1.60$)$ \\
\hline $1 / 2$ & $80 / 104368$ & 2.37 (1.80 to 3.12$)$ & 2.01 (1.51 to 2.67$)$ & 1.56 (1.16 to 2.08$)$ \\
\hline Pvalue§ & & $<0.001$ & $<0.001$ & 0.003 \\
\hline SD decrease & 425/1 109050 & $1.49(1.35$ to 1.64$)$ & 1.38 (1.24 to 1.53$)$ & $1.18(1.05$ to 1.32$)$ \\
\hline Pvalue & & $<0.001$ & $<0.001$ & 0.004 \\
\hline \multicolumn{5}{|c|}{ Jumping or falling from a high place } \\
\hline $7-9$ & $59 / 286450$ & 0.69 (0.50 to 0.93$)$ & 0.67 (0.49 to 0.93$)$ & $0.83(0.60$ to 1.16$)$ \\
\hline $5 / 6$ & $127 / 443385$ & 1.00 (reference) & 1.00 (reference) & 1.00 (reference) \\
\hline $3 / 4$ & $117 / 274889$ & $1.44(1.12$ to 1.85$)$ & $1.42(1.10$ to 1.83$)$ & $1.24(0.95$ to 1.60$)$ \\
\hline $1 / 2$ & $70 / 104378$ & 2.24 (1.67 to 3.00$)$ & $2.00(1.48$ to 2.71$)$ & $1.62(1.19$ to 2.21$)$ \\
\hline Pvalue§ & & $<0.001$ & $<0.001$ & 0.004 \\
\hline SD decrease & 373/1 109102 & $1.48(1.34$ to 1.64$)$ & $1.44(1.29$ to 1.61$)$ & $1.27(1.12$ to 1.43$)$ \\
\hline Pvalue & & $<0.001$ & $<0.001$ & $<0.001$ \\
\hline \multicolumn{5}{|c|}{ Firearms and explosives } \\
\hline $7-9$ & $32 / 286477$ & 0.65 (0.43 to 0.99$)$ & $0.79(0.51$ to 1.20$)$ & $1.10(0.71$ to 1.69$)$ \\
\hline $5 / 6$ & $74 / 443438$ & 1.00 (reference) & 1.00 (reference) & 1.00 (reference) \\
\hline $3 / 4$ & $65 / 274941$ & $1.37(0.98$ to 1.91$)$ & $1.19(0.85$ to 1.67$)$ & $1.02(0.72$ to 1.43$)$ \\
\hline $1 / 2$ & 47/104 401 & 2.61 (1.81 to 3.76$)$ & 1.96 (1.34 to 2.86$)$ & $1.58(1.08$ to 2.31$)$ \\
\hline Pvalue§ & & $<0.001$ & 0.002 & 0.12 \\
\hline SD decrease & $218 / 1109257$ & $1.58(1.38$ to 1.80$)$ & $1.37(1.18$ to 1.58$)$ & $1.16(1.00$ to 1.36$)$ \\
\hline Pvalue & & $<0.001$ & $<0.001$ & 0.06 \\
\hline \multicolumn{5}{|l|}{ Drowning } \\
\hline $7-9$ & $17 / 286492$ & 0.72 (0.40 to 1.28$)$ & 0.68 (0.38 to 1.23$)$ & $0.68(0.37$ to 1.25$)$ \\
\hline $5 / 6$ & $35 / 443477$ & 1.00 (reference) & 1.00 (reference) & 1.00 (reference) \\
\hline $3 / 4$ & $32 / 274974$ & 1.42 (0.88 to 2.29$)$ & 1.44 (0.88 to 2.34$)$ & 1.44 (0.88 to 2.38$)$ \\
\hline $1 / 2$ & $21 / 104427$ & $2.43(1.42$ to 4.18$)$ & 2.35 (1.34 to 4.13$)$ & $2.37(1.32$ to 4.25$)$ \\
\hline Pvalue§ & & $<0.001$ & 0.003 & 0.01 \\
\hline SD decrease & $105 / 1109370$ & $1.49(1.23$ to 1.80$)$ & $1.50(1.22$ to 1.85$)$ & $1.52(1.21$ to 1.91$)$ \\
\hline Pvalue & & $<0.001$ & $<0.001$ & $<0.001$ \\
\hline
\end{tabular}

SES=socioeconomic status.

*Intentional and undetermined injuries combined.

TAdjusted for age, conscription centre, year of birth, childhood SES, adult SES, height, body mass index, and systolic blood pressure.

‡Adjusted for age, conscription centre, year of birth, childhood SES, adult SES, height, body mass index, systolic blood pressure, and educational attainment.

$\S \mathrm{P}$ for trend. 
for age only $1.58,1.47$ to 1.69 ; adjusted for age and risky alcohol use $1.49,1.39$ to 1.60 ; and adjusted for age and smoking 1.50, 1.40 to 1.61). We found similar results for poisoning by solid or liquid and for injuries from sharp objects; numbers of events were insufficient to allow us to look separately at other method specific suicide attempts.

Of 12328 men identified as psychotic, 1607 (13.0\%) had at least one subsequent admission for attempted suicide compared with 16129 (1.5\%) men free from psychosis. The figure shows age adjusted associations between IQ and attempted suicide by any means for men with and without psychosis. The association in men free from psychosis was very similar to that shown in table 3 , with stepwise increases in hazard associated with decreasing IQ score (age adjusted hazard ratio for an $\mathrm{SD}$ decrease in $\mathrm{IQ}=1.73,1.70$ to 1.75). In contrast, we found no evidence of any association between IQ and attempted suicide in men with psychosis, and confidence intervals for all IQ scores included 1.0. Statistical tests for interaction/effect modification were highly significant $(\mathrm{P}<0.001)$. Analyses of method specific attempted suicides were very similar: for all seven specific methods we found consistently strong associations of increasing risk of attempted suicide with decreasing IQ score in men free from psychosis compared with no marked associations between IQ and attempted suicide in men with psychosis (results available on request).

In analyses of the four IQ subscales, the strongest associations with attempted suicide by any means were those with the logical subtest (age adjusted hazard ratio for an $\mathrm{SD}$ decrease in logical $\mathrm{IQ}=1.68,1.65$ to $1.70)$, followed by the technical subscale (1.61, 1.59 to 1.64$)$, verbal subscale $(1.52,1.50$ to 1.54$)$, and spatial subscale $(1.49,1.47$ to 1.52$)$. This somewhat stronger association with logical IQ was also apparent for all method specific suicide attempts other than jumping or falling from a high place. Finally, results from analyses excluding undetermined injuries or based on Poisson regression were very similar to those presented here.

\section{DISCUSSION}

In this large scale, prospective cohort study, we found strong, consistent, stepwise associations between decreasing IQ score and increasing risk of attempted suicide, which were evident for attempted suicide by any means and for seven specific methods. Adjustment for childhood and adult socioeconomic status and, to a greater extent, education led to a reduction in magnitude, but strong associations remained in multiply adjusted models. Separate analyses suggested that associations between IQ and attempted suicide were restricted to men without psychosis; in men with psychosis we found no evidence of any marked association between IQ and attempted suicide.

\section{Strengths and limitations}

Our analyses are based on an almost complete birth cohort of more than one million men followed up for an average of 24 years. This study is considerably larger than others in the field, which, in addition to providing superior statistical power, has enabled us to consider method specific attempted suicides. These method specific analyses were motivated, a priori, by observations that the method of preference, often determined by availability, varies with (among other factors) occupation and socioeconomic status, ${ }^{30}$ which are related to IQ. Our study population had IQ measured using standardised tests in early adulthood and is well characterised for socioeconomic status and other potential confounding or mediating factors. A potential problem of working with IQ scores collected over 25 years is the "Flynn effect," ${ }^{11}$ which describes the phenomenon, in nationally representative samples, of rising IQ scores over time. However, the IQ scores used in these analyses were standardised year on year, and, as a result, we are confident that the Flynn effect had no impact.

We identified attempted suicides from hospital admissions, and, as hospital treatment in Sweden is free, we have no reason to suppose that any systematic bias resulted from this approach. However, our analyses do not include incidents of self harm that did not need hospital treatment, which may be important in identifying people at future risk of attempted or completed suicide. Additionally, our analyses are based on admissions for attempted suicide in Swedish men aged 16 to 57 , and our results are not necessarily generalisable to other countries, to women, or to older men. However, younger people have been identified as a priority in terms of suicide prevention, and our results provide an insight into this particularly important group.

Psychosis is a well established risk factor for attempted suicide, and men who were psychotic at the time of conscription might have performed poorly on the IQ test as a result. However, the vast majority $(97.7 \%)$ of cases of psychosis were identified after conscription, minimising the confounding effect of this factor on our results. Finally, almost 20\% of men were excluded from analyses, mostly because of missing IQ, and fewer attempted suicides occurred in this group. Educational achievement was generally lower, suggesting that excluded men may have been in the lower IQ range. The lower attempted suicide rates in these men therefore suggest that our hazard ratios may be slight overestimates. However, their magnitude is consistent with those reported elsewhere, ${ }^{68}$ and the stepwise nature of the associations across all nine IQ scores make it very unlikely that they are substantially due to selection bias.

\section{Possible explanations for associations}

Several plausible explanations exist for the associations between IQ and attempted suicide presented here. Low IQ tends to correlate with lower socioeconomic status and income, so people with lower IQ scores may experience more social and financial disadvantage, leading to an increase in suicidal thoughts and behaviours. Low IQ has also been associated with poor 


\section{WHAT IS ALREADY KNOWN ON THIS TOPIC}

Evidence is emerging of an association between intelligence (IQ) and attempted (non-fatal) suicide

Existing studies are relatively small and have not explored the association of IQ with method specific attempted suicides

Very little is known about the potential effect modifying role of psychosis on associations between IQ and attempted suicide

\section{WHAT THIS STUDY ADDS}

In a cohort of over one million men, strong stepwise associations existed between decreasing IQ score in young adulthood and increasing attempted suicide in men free from psychosis

These associations were evident for suicide attempts by any means and for seven specific attempted suicide methods

No such associations existed in men with psychosis

health behaviours such as binge drinking, ${ }^{28}$ which also increases suicide risk. ${ }^{29}$ In our analyses, adjustment for socioeconomic status, smoking, and risky alcohol use led to small degrees of attenuation, suggesting that these factors may partially confound or mediate associations between IQ and attempted suicide. However, the attenuation was modest and these factors are unlikely to account completely for the observed associations.

IQ may also influence a person's ability to deal with stressful circumstances or traumatic events; studies in children and adolescents suggest that those of higher intelligence are more resilient to stress. ${ }^{3233}$ People with lower IQ scores may have poorer problem solving abilities and, in times of crisis, be less able to identify practical solutions to their problems. ${ }^{10}$ In separate analyses of the four IQ subtests, we found that associations with the logical (problem solving) subscale were consistently strongest, which would support this view. We also found strong associations with the verbal IQ component, suggesting that an ability to verbalise and share emotion or distress might reduce the risk of non-verbal expression such as self harm. Studies in children suggest that higher cognitive ability is associated with a greater internal locus of control, ${ }^{34}$ leading to a decrease in the risk of suicidal behaviour. ${ }^{35}$ In addition, high emotional intelligence, particularly strategic emotional intelligence (defined as the ability to understand and manage emotions) may also reduce suicidal behaviour. $^{36}$

Adversity in childhood may also affect IQ or academic performance and future suicide risk. Children exposed to violence early in life, either directly as victims or indirectly as witnesses, have been found to have reduced cognitive function, ${ }^{3738}$ and studies of community violence and those that attempt to control for genetic influences indicate that suppression of IQ in exposed children may be independent of parental IQ. ${ }^{3940}$ Exposure to direct or indirect violence in childhood has also been reported to increase the risk of suicide ideation or attempts later in life. ${ }^{4142}$ Although speculative, these relations may contribute to associations between IQ and attempted suicide, and the hypothesis may be worthy of further investigation.

Finally, we need to consider the role of psychosis. Previous studies of completed suicide suggest that associations with IQ may differ between people with and without psychosis. Specifically, whereas lower IQ is a risk factor for suicide in those free from psychosis, low IQ or poor school performance has been observed to reduce the risk of completed suicide in psychotic people. ${ }^{1215}$ Possible explanations include higher self expectation in people with higher IQ, leading to increased distress in the face of mental disintegration or greater downward drift in socioeconomic status after mental illness. ${ }^{14}$ The negative effect of low IQ in our analysis was similarly restricted to men without psychosis. However, in men with psychosis, we found a lack of association between IQ and attempted suicide rather than the negative impact of high IQ reported for completed suicides. ${ }^{1214}$ This is a new observation, which needs to be replicated in other populations, and speculating on the reasons underlying it is difficult. Inevitably, analyses in psychotic men were based on smaller numbers, possibly leading to reduced power; however, attempted suicide was markedly more common in these men and, in practice, we had $90 \%$ power to detect a $20 \%$ difference between men with below and above average IQ, which is an extremely modest effect in this context. Alternatively, the apparent lack of association with IQ in men with psychosis may simply reflect the strength of associations between psychosis and attempted suicide compared with the relatively negligible effect of other risk factors.

\section{Conclusions}

Suicide is a major cause of morbidity and mortality at young adult ages and therefore presents an important public health challenge. However, the causes of attempted and completed suicide are very poorly understood. This study confirms an emerging association between IQ and attempted suicide in a much larger dataset than has previously been used in this context and, uniquely, provides insight into the role of psychosis. A greater understanding of IQ-suicide associations, particularly in the presence or absence of psychosis, provides a novel insight into the process by which people come to make the decision to attempt suicide. Given the novelty of these findings, further research is needed to provide a deeper understanding, which will inform public health strategies and may lead to a reduction in future attempted and subsequently completed suicides.

Contributors: All authors contributed to the design and interpretation of the study, critically revised the manuscript, and approved the final version. EW did the statistical analyses, and GDB and EW wrote the first draft. EW, PT, and FR are the guarantors.

Funding: GDB is a Wellcome Trust fellow (WBS U

1300.00.006.00012.01), funding from which also supports EW. The Medical Research Council (MRC) Social and Public Health Sciences Unit receives funding from the UK MRC and the Chief Scientist Office at the Scottish Government Health Directorates. The Centre for Cognitive Ageing and Cognitive Epidemiology is supported by the Biotechnology and Biological Sciences Research Council, the Engineering and Physical 
Sciences Research Council, the Economic and Social Research Council, the MRC, and the University of Edinburgh as part of the cross council lifelong health and wellbeing initiative. FR is supported by the Swedish Research Council, the Labour Market Insurance Ltd (AFA), and the Swedish Council for Working Life and Social Research.

Competing interests: None declared.

Ethical approval: The Regional Ethics Committee, Stockholm, approved the study.

Data sharing: No additional data available

1 Schmidtke A, Bille-Brahe U, Deleo D, Kerkhof A, Bjerke T, Crepef P, et al. Attempted suicide in Europe: rates, trends and sociodemographic characteristics of suicide attempters during the period 1989-1992. Results of the WHO/EURO multicentre study on parasuicide. Acta Psychiatr Scand 1996;93:327-38.

2 Claassen CA, Trivedi MH, Shimizu I, Stewart S, Larkin GL, Litovitz T. Epidemiology of nonfatal deliberate self-harm in the United States as described in three medical databases. Suicide Life Threat Behav 2006;36:192-212.

3 Owens D, Horrocks J, House A. Fatal and non-fatal repetition of selfharm: systematic review. Br J Psychiatry 2002;181:193-9.

4 Voracek M. National intelligence and suicide rate: an ecological study of 85 countries. Pers Individ Dif 2004:37:543-53.

5 Voracek M. National intelligence, suicide rate in the elderly, and a threshold intelligence for suicidality: an ecological study of 48 Eurasian countries. / Biosoc Sci 2005;37:721-40.

6 Jiang G-X, Rasmussen F, Wasserman D. Short stature and poor psychological performance: risk factors for attempted suicide among Swedish male conscripts. Acta Psychiatr Scand 1999:100:433-40.

7 Fergusson DM, Horwood LI, Ridder EM. Show me the child at seven II: childhood intelligence and later outcomes in adolescence and young adulthood. J Child Psychol Psychiatr 2005;46:850-8.

8 Osler M, Nybo Andersen AM, Nordentoft M. Impaired childhood development and suicidal behaviour in a cohort of Danish men born in 1953. J Epidemiol Community Health 2008;62:23-8.

9 O’Toole BI, Cantor C. Suicide risk factors among Australian Vietnam era draftees. Suicide Life Threat Behav 1995;25:475-88.

10 Gunnell D, Magnusson PKE, Rasmussen F. Low intelligence test scores in 18 year old men and risk of suicide: cohort study. $B M J$ 2004;330:167-70.

11 Hemmingsson T, Melin B, Allebeck P, Lundberg I. The association between cognitive ability measured at ages 18-20 and mortality during 30 years of follow-up - a prospective observational study among Swedish males born 1949-51. Int I Epidemiol 2006;35:665-70.

12 Andersson L, Allebeck P, Gustafsson JE, Gunnell D. Association of IQ scores and school achievement with suicide in a 40-year follow-up of a Swedish cohort. Acta Psychiatr Scand 2008;118:99-105.

13 Gale CR, Deary IJ, Boyle SH, Barefoot J, Mortensen LH, Batty GD. Cognitive ability in early adulthood and risk of 5 specific psychiatric disorders in middle age: the Vietnam Experience Study. Arch Gen Psychiatry 2008;65:1410-8.

14 Hawton K, Sutton L, Haw C, Sinclair J, Deeks JJ. Schizophrenia and suicide: systematic review of risk factors. Br J Psychiatry 2005;187:9-20.

15 Alaraisanen A, Miettunen J, Lauronen E, Rasanen P, Isohanni M. Good school performance is a risk factor of suicide in psychoses: a 35-year follow up of the Northern Finland 1966 birth cohort. Acta Psychiatr Scand 2006;114:357-62.

16 Batty GD, Wennerstad KM, Smith GD, Gunnell D, Deary IJ, Tynelius P, et al. IQ in early adulthood and later cancer risk: cohort study of one million Swedish men. Ann Oncol 2007;18:21-8.

17 Zammit S, Allebeck P, David AS, Dalman C, Hemmingsson T, Lundberg I, et al. A longitudinal study of premorbid IQ score and risk of developing schizophrenia, bipolar disorder, severe depression, and other nonaffective psychoses. Arch Gen Psychiatry 2004;61:354-60.

18 Hemmingsson T, Lundberg I. How far are socioeconomic differences in coronary heart disease hospitalization, all-cause mortality and cardiovascular mortality among adult Swedish males attributable to negative childhood circumstances and behaviour in adolescence? Int J Epidemiol 2005;34:260-7.
19 Linsley KR, Schapira K, Kelly TP. Open verdict v suicide-importance to research. BrJ Psychiatry 2001;178:465-8.

20 Brock A, Griffiths C. Trends in suicide by method in England and Wales, 1979 to 2001. Health Stat Q 2003;20:7-17.

21 Biddle L, Brock A, Brookes ST, Gunnell D. Suicide rates in young men in England and Wales in the 21st century: time trend study. BMJ 2009;336:539-42

22 Gunnell D. Can adult anthropometry be used as a biomarker for prenatal and childhood exposures? Int J Epidemiol 2002;31:390-4.

23 Starr IM, Taylor MD, Hart CL, Davey Smith G, Whalley LJ, Hole DJ, et al. Childhood mental ability and blood pressure at midlife: linking the Scottish Mental Survey 1932 and the Midspan studies. J Hypertens 2004;22:893-7.

24 Chandola T, Deary IJ, Blane D, Batty GD. Childhood IQ in relation to obesity and weight gain in adult life: the National Child Development (1958) Study. Int J Obes 2006;30:1422-32.

25 Terry PD, Abramson JL, Neaton JD, MRFIT Research Group. Blood pressure and risk of death from external causes among men screened for the Multiple Risk Factor Intervention Trial. Am J Epidemiol 2007;165:294-301.

26 Bjerkeset O, Romundstad P, Evans J, Gunnell D. Association of adult body mass index and height with anxiety, depression, and suicide in the general population: the HUNT study. Am J Epidemiol 2008;167:193-202.

27 Batty GD, Deary IJ, Schoon I, Emslie C, Hunt K, Gale CR. Childhood mental ability and adult alcohol intake and alcohol problems: the 1970 British Cohort Study. Am I Public Health 2008;98:2237-43.

28 Batty GD, Deary IJ, MacIntyre S. Childhood IQ and life course socioeconomic position in relation to alcohol induced hangovers in adulthood: the Aberdeen children of the 1950s study. J Epidemiol Community Health 2006;60:872-4.

29 Rehm J, Room R, Graham K, Monteiro M, Gmel G, Sempos CT. The relationship of average volume of alcohol consumption and patterns of drinking to burden of disease: an overview. Addiction 2003;98:1209-28.

30 Kelly S, Bunting J. Trends in suicide in England and Wales, 1982-96. Popul Trends 1998;92:29-41.

31 Flynn JR. Massive IQ gains in 14 nations: what IQ tests really measure. Psychol Bull 1987;101:171-91.

32 Masten AS, Coatsworth JD, Neemann J, Gest SD, Tellegen A, Garmezy N. The structure and coherence of competence from childhood through adolescence. Child Dev 1995;66:1635-59.

33 Fergusson DM, Lynskey MT. Adolescent resiliency to family adversity. J Child Psychol Psychiatr 1996;37:281-92.

34 Gale CR, Batty GD, Deary II. Locus of control at age 10 years and health outcomes and behaviors at age 30 years: the 1970 British Cohort Study. Psychosom Med 2008;70:397-403.

35 Pearce CM, Martin G. Locus of control as an indicator of risk for suicidal behaviour among adolescents. Acta Psychiatr Scand 1993;88:409-14.

36 Cha CB, Nock MK. Emotional intelligence is a protective factor for suicidal behaviour. J Am Acad Child Adolesc Psychiatry 2009;48:422-30.

37 Malinosky-Rummell R, Hansen DJ. Long-term consequences of childhood physical abuse. Psychol Bull 1993;114:68-79.

38 Kolbo JR, Blakely EH, Engleman D. Children who witness domestic violence: a review of empirical literature. J Interpers Violence 1996;11:281-93.

39 Delaney-Black V, Covington C, Ondersma SJ, Nordstrom-Klee B, Templin T, Ager J, et al. Violence exposure, trauma, and IQ and/o reading deficits among urban children. Arch Pediatr Adolesc Med 2002;156:280-5.

40 Koenen KC, Moffitt TE, Caspi A, Taylor A, Purcell S. Domestic violence is associated with environmental suppression of IQ in young children. Dev Psychopathol 2003;15:297-311.

41 Afifi TO, Enns MW, Cox BJ, Asmundson GJG, Stein MB, Sareen I. Population attributable fractions of psychiatric disorders and suicide ideation and attempts associated with adverse childhood experiences. Am J Public Health 2008;98:946-52.

42 Enns MW, Cox BJ, Afifi TO, De Graff R, Have MT, Sareen J. Childhood adversities and risk for suicidal ideation and attempts: a longitudinal population-based study. Psychol Med 2006;36:1769-78.

Accepted: 9 March 2010 